\title{
Forschungsberichte
}

\section{Singing Abilities and Phonological Awareness in 9- to 12-Year-Old Children}

\author{
Singfähigkeit und Phonologische Bewusstheit bei 9- bis 12-Jährigen Kindern
}

\section{Franziska Degé ${ }^{\star}$, Daniel Müllensiefen ${ }^{b}$, Gudrun Schwarzera}

[a] Developmental Psychology, Justus-Liebig-Universität Gießen, Gießen, Germany. [b] Psychology, Goldsmiths College, University of London, London, United Kingdom.

\begin{abstract}
Music and language seem to be associated strongly in the early years of development. We do not know at which time point in development this association weakens. Therefore, this longitudinal study investigated whether singing abilities (song reproduction) are associated with phonological awareness in secondary school children. Furthermore, we tested whether singing ability can predict the development of phonological awareness over a time course of two years in 9- to 12-year-old children. We found that song learning abilities were significantly correlated with phonological awareness scores at all three test waves across the two-year duration of the study. Beyond that, it was possible to predict phonological awareness over time with singing abilities. The model that - in addition to the time of the test wave only employed song learning abilities and IQ as predictors showed the best fit to the data and represents a parsimonious explanatory model of the development of phonological awareness in 9- to 12-year old children and its relationship with singing ability.
\end{abstract}

Keywords: phonological awareness, singing, children, musical abilities

\section{Zusammenfassung}

Musik und Sprache weisen in den ersten Jahren der Kindesentwicklung einen starken Zusammenhang auf. Es ist bisher unklar bis zu welchem Zeitpunkt in der Entwicklung dieser starke Zusammenhang anhält. Daher ist es das Ziel dieser Studie, den Zusammenhang zwischen Singfähigkeiten (Liedreproduktion) und phonologischer Bewusstheit in Schülern der Sekundarstufe zu untersuchen. Darüber hinaus wurde untersucht, ob die Singfähigkeiten von 9- bis 12-jährigen Kindern die Entwicklung der phonologischen Bewusstheit über einen Zeitraum von 2 Jahren vorhersagen kann. Es zeigte sich ein signifikanter Zusammenhang zwischen Singfähigkeit und der phonologischen Bewusstheit zu allen drei Messzeitpunkten (verteilt über 2 Jahre). Außerdem war es möglich die phonologische Bewusstheit durch die Singfähigkeiten vorherzusagen. Das Model, das (zusätzlich zum Messzeitpunkt) Singfähigkeiten und IQ für die Vorhersage der phonologischen Bewusstheit nutzte, hatte die beste Passung mit den Daten und scheint somit am geeignetsten zu sein, die Entwicklung der phonologischen Bewusstheit und ihren Zusammenhang mit Singfähigkeiten bei 9- bis 12-jährigen Kindern zu beschreiben.

Schlüsse/wörter: phonologische Bewusstheit, Singen, Kinder, musikalische Fähigkeiten

Jahrbuch Musikpsychologie, 2020, Vol. 29, Artikel e66, https://doi.org/10.5964/jbdgm.2019v29.66

Eingereicht: 2019-09-26. Akzeptiert: 2020-09-14. Publiziert (VoR): 2020-10-22.

Begutachtet von: Friedrich Platz; Stephan Sallat.

*Korrespondenzanschrift: Developmental Psychology, Justus-Liebig-University Gießen, Otto-Behaghel-Straße 10F, 35394 Gießen, Germany. E-Mail: franziska.dege@ae.mpg.de

Dieser Open-Access-Artikel steht unter den Bedingungen einer Creative Commons Namensnennung 4.0 International Lizenz, CC BY 4.0 (https://creativecommons.org/licenses/by/4.0/deed.de). Diese erlaubt für beliebige Zwecke (auch kommerzielle) den Artikel zu verbreiten, in jedwedem Medium zu vervielfältigen, Abwandlungen und Bearbeitungen anzufertigen, unter der Voraussetzung, dass der Originalartikel angemessen zitiert wird.

For the acquisition of literacy skills entering school is not the starting point: In the case of learning to read, developmental studies have already in kindergarten identified phonological awareness as one important pre- 
cursor of literacy skills (Jansen, Mannhaupt, Marx, \& Skowronek, 2002). Phonological awareness, in short, is the knowledge that language is based on phonemes and refers to the skill to analyze and manipulate phonemes. Research has demonstrated that music and language seem to be associated strongly in the early years of development (Koelsch \& Siebel, 2005; McMullen \& Saffran, 2004). For example, in 4-year-old children phonological awareness is correlated with musical abilities with $r=.59$ (Anvari, Trainor, Woodside, \& Levy, 2002). Later, in adulthood, they seem less tightly connected (Peretz \& Coltheart, 2003), although they still might rely on the same neuronal processes (Patel, 2008). This developmental trajectory is particularly interesting, because the two abilities start off as being closely associated and develop in more distinct ways in adulthood. However, we do not know at which age the association weakens or might change in nature.

Therefore, the aims of this study were twofold; first we investigated whether a musical ability (i.e., singing) was associated with phonological awareness also in secondary school children. Second, we investigated whether singing abilities can predict the further development of phonological awareness.

\section{Phonological Awareness}

Phonological awareness describes the insight into the phonological structure of our language (Jansen et al., 2002). It refers to the skill to analyze phonemes and manipulate words. Phonological awareness can be segmented into phonological awareness for large phonological units (words and syllables) and phonological awareness for small phonological units (phonemes; Jansen et al., 2002; Skowronek \& Marx, 1989). The developmental trajectory of these two aspects differs: Phonological awareness of large phonological units emerges spontaneously during the kindergarten period, whereas the development of phonological awareness for small phonological units is typically linked to reading and writing instruction in school (Küspert \& Schneider, 2005). It has been shown repeatedly that phonological awareness is the most important precursor of learning to read and write (Bruck, 1992; Jansen et al., 2002; Pratt \& Brady, 1988). Since this precursor has an outstanding role for acquiring literacy, several training programs have been established (e.g., hören, lauschen, lernen) (Küspert \& Schneider, 2005). These training programs have been shown to train phonological awareness successfully and facilitate the process of learning to read and write (Schneider, Kuspert, Roth, Vise, \& Marx, 1997; Schneider, Roth, Küspert, \& Ennemoser, 1998). Once the skill to read is acquired, phonological awareness is no longer as important to the further development of literacy as before. From then on a letter based approach for reading and writing is more important (Marx, 2007). However, phonological awareness is a skill that can still be measured in older children although it loses its primary role in learning to read and write.

\section{Explanations for the Association Between Phonological Awareness and Music}

Explanations for the associations between phonological awareness and musical abilities are mostly based on the functional overlap of brain structures that are involved in music and speech processing (Besson, Chobert, \& Marie, 2011). This means that domain-general abilities used for music and speech processing might form the basis of the connection between music and language. Within this framework several theoretical approaches offer explanations for associations between musical abilities and phonological awareness.

Patel (2008) postulated a shared sound category learning mechanism. In his opinion musical and language sound systems face a similar challenge: the extraction of a small number of meaningful categories from an acoustic input stream. This challenge is mastered using one process; the so-called shared sound category learning mechanism. However, while Patel postulates that the same mechanisms are underlying music and 
speech processing, he believes that input from these two domains still can be processed in partly different brain areas. Patel's hypothesis predicts that the sensitivity for sound categories in music and language are related and implies a correlation between phonological awareness and musical abilities (mainly pitch related abilities).

A different theoretical approach focuses on connections between phonological awareness and musical abilities on a more basic level: the sensitivity for acoustical features (Besson et al., 2011). Musicians have an enhanced sensitivity to auditory parameters such as frequency and duration that are important for music processing. Because in speech as well as in music processing of these parameters is important, the training in one domain can also promote the performance in the other domain. As a consequence, the greater auditory sensitivity of musicians can result in a more elaborate auditory perception of speech. This beneficial enhancement on lower levels of processing can also be advantageous for higher levels of speech processing (e.g., phonological processing).

Similarly, the path model by Tierney and Kraus (2014) also focuses on the connection of basic auditory features to explain associations between musical abilities and phonological awareness. Tierney and Kraus (2014) put forward the precise auditory timing hypothesis that emphasizes the connection between auditory motor entrainment and phonological skills. They assume that music training requires entrainment, and entrainment necessitates the precise perception of acoustic event timing. Hence, musical training over extended periods of time might result in higher precision of timing in the automated representation of acoustic events in the auditory system. This higher precision benefits speech sound perception, which is important for phonological skills.

In addition to these models that focus on a few concrete features shared by music and language, Patel (2011) has formulated the OPERA hypothesis, a framework that explains how different factors contribute to the relationships between music and language at a general level. The five OPERA factors, Overlap, Precision, Emotion, Repetition, and Attention, are features of music or music making that enable transfer effects of music to language. Overlapping brain networks build the basis for a sensory or cognitive process that is used for music and speech. This process is used with a higher demand on precision by music than by language. Finally, music engages this process with emotion (music is emotionally rewarding), repetition (music relies on repetition for learning) and attention (music needs a high amount of attention).

Developmentally, music and language might have a common basis in the early years of development (Koelsch \& Siebel, 2005; McMullen \& Saffran, 2004). This assumption is supported on different levels. Regarding communications between infants and caregivers similar adjustments by social interaction partners (infant-directed speech and infant-directed singing) are made for music and language and infants prefer these forms of infant-directed speech and singing from an early age onward (Masataka, 1999; Trainor, 1996). Similarly, infant-directed speech resembles musical speech to a large degree (Fernald, 1991). This is in accordance with Koelsch and Siebel (2005) notion that the early developing brain processes language as a kind of music. Also, infants' sound productions mirror this development. Until the second year of life it is difficult to disentangle singing from speaking in the infants productions (Stadler-Elmer, 2002). Hence, in the early years of life a strong connection between music and language is obvious. However, it is unclear until what age they remain strongly associated. Similarly, it is important to know until what age music might be a promising tool to influence language development. The training studies reviewed in the following section provide an indication of the age range where music may have a beneficial impact on language development. 


\section{Music Training and Phonological Awareness}

Several studies have investigated the influence of music training on phonological awareness in 4- to 6-year-old children. They revealed significantly greater gains in phonological awareness for kindergarten children in the music treatment group compared to a control group (Degé \& Schwarzer, 2011; Gromko, 2005; Herrera, Lorenzo, Defior, Fernandez-Smith, \& Costa-Giomi, 2011; Patscheke, Degé, \& Schwarzer, 2016). Furthermore, it was found that the more intense music training benefited phonological awareness more (Bolduc, 2009; Moritz, Yampolskiy, Papadelis, Thomson, \& Wolf, 2013). In a study with school-aged children (8 to 10 years) Chobert, François, Velay, and Besson (2014) showed an increase in pre-attentive processing of the duration of syllables and the voice onset time of syllables. Their results highlight the potential influence of musical training on the development of phonological representations in children. Furthermore, these results might be interpreted as pointing towards a persistent association between phonological skills and music training even after the preschool years. The understanding of the positive impact of music training on phonological awareness is important, because it suggests that music training can be used to complement already existing phonological skills training programs. A claim that also finds modest support by a meta-analysis indicating that music training promotes phonological skills but not reading fluency (Gordon, Fehd, \& McCandliss, 2015).

\section{Musical Abilities and Phonological Awareness}

Several studies (Anvari et al., 2002; Degé, Kubicek, \& Schwarzer, 2015; Lamb \& Gregory, 1993; Norton et al., 2005) have revealed an association between musical abilities or musical aptitude and phonological awareness for large as well as for small phonological units. In sum, these studies show that temporal abilities like rhythmic or metrical abilities are associated with phonological awareness for small phonological units (phonemes; Flaugnacco et al., 2014) and large phonological units (rhyming; Huss, Verney, Fosker, Mead, \& Goswami, 2011). In addition, Lamb and Gregory (1993) showed significant associations of pitch related skills with a battery of phonological awareness comprising subtests for large and small phonological units. Degé and colleagues (2015) investigated the associations between musical abilities and phonological skills in greater detail and found that music perception as well as music production abilities were related to phonological awareness for large and small phonological units. A similar detailed approach was applied in two cross-sectional studies with children of two age groups (preschoolers and third-graders) that investigated associations between rhythmical as well as tonal musical skills and phonological awareness and literacy (Steinbrink, Knigge, Mannhaupt, Sallat, \& Werkle, 2019). In both age groups rhythmical and tonal musical skills were associated with phonological awareness. In the preschool sample phonological awareness for large and small units was related to rhythm (large units were also associated with tonal skills), whereas in the sample of third-graders only phonological awareness for small units was related to rhythmical skills. Interestingly, in the study by Degé et al. (2015), the correlations between music production abilities and phonological awareness were higher than those between music perception abilities and phonological awareness. Among the musical production abilities, the skill to sing a song had a prominent position, because it was correlated with the total score of phonological awareness as well as with nearly all subtests (two subtests assessing large phonological units and one assessing small phonological units) contained in the total score (range of correlations: $.34<r<.53$ ). This points towards a general and prominent relationship between singing and phonological awareness. 


\section{Singing and Phonological Awareness}

The development of singing is characterized by a gradual age-related change in the accuracy of singing abilities and the vocal register (Welch, 2012). However, this development is highly variable because the opportunity to sing, the family background, the amount of instruction, and the value attributed to singing skills all play a role in the developmental trajectory. At the age of two children start to sing along with children's songs performed by adults. They produce parts of the song and imitate the adult model. With three years of age children merge phrases of songs together to form the whole song. They get better at reproducing correct pitch intervals. With four years children are able to produce recognizable songs and start to master intervals and metre. Six- to 7-year-old children produce songs in the range of an octave. Davidson, for example, assumes that with eight years the development of singing skills is nearly complete (Davidson, 1994).

This close relationship between singing and phonological awareness might be a consequence of singing giving a unique way to access phonemes: Song lyrics consist of words and syllables. When sung, these are stressed, repeated or lengthened. These manipulations guide children's attention to individual sounds of speech (i.e., phonological awareness; Fisher \& McDonald, 2001). This notion is also in accordance with structural elements of typical children's songs, which contain simple lyrics and make use of rhyme very frequently. Hence, music and speech are inextricably linked with music providing an opportunity to highlight aspects of speech. Children's songs have a simple and repetitive structure that may facilitate linguistic processing. A study with adults who learn a new language points in a similar direction: Schön et al. (2008) found a clear advantage for language learning based on sung verbal sequences compared to spoken sequences (Schön et al., 2008). The authors theorise that boundary enhancement in the sung sequences plays a crucial role in language learning and that melodic and or prosodic information may facilitate grouping or segmentation. Furthermore, this idea is supported by a study by Bryant, Bradley, Maclean, and Crossland (1989). Their longitudinal study tested 3-year-old children and found a strong relation between children's early knowledge of nursery rhymes and their phonological sensitivity over the next three years. This may be interpreted as a first hint that singing abilities, rudimentarily measured as knowledge of nursery rhymes, may be predictive of phonological skills at least in that young age. A training study with preschoolers also found evidence for the notion of a unique access of singing to phonological awareness. They revealed a positive influence of a music training program that focused on singing and intonation on phonological skills (Patscheke, Degé, \& Schwarzer, 2019). They assigned preschoolers randomly to a rhythm training that comprised rhythmic exercises (like drumming) and rhythmic listening tasks, a pitch training that had a focus on singing and interval perception, and a sports control group. Preschoolers were trained for 16 weeks and their phonological awareness was measured before and after training. The pitch training that heavily relied on singing and intonation training was most effective in enhancing phonological awareness. The rhythm intervention also produced a small effect, although it did not reach the common levels of significance. This shows that the association between singing ability phonological sensitivity in 3-year-olds (Bryant et al., 1989) can be exploited to train phonological skills in preschoolers. However, the intervention used by Patscheke et al. (2019) did not solely consist of singing but also included intonation and listening tasks. Therefore, it is unclear whether singing alone can promote phonological skills.

\section{Objectives}

The evidence presented so far shows that among the music production skills that are associated with phonological awareness, singing might have a prominent role (Degé et al., 2015). It is highly likely that singing is 
associated with phonological skills, however, what remains unclear is for how long (i.e., until what age) the association between phonological skills and singing remains evident. Moreover, to clearly link singing to phonological skills singing abilities should be assessed directly, not only indirectly through the knowledge of nursery rhymes, as in the study by Bryant and colleagues (1989). Therefore, we ran a two-year longitudinal study with 9- to 12-year-old children in which we measured phonological skills and assessed singing skills. This approach will tell us whether phonological skills and musical skills are still associated in children attending secondary school and whether singing abilities can predict phonological abilities in this age group. We hypothesize that there is a significant positive association between singing abilities and phonological awareness in secondary school children. Also, we assume that it is possible to predict phonological awareness scores statistically from singing ability scores (over the time course of at least one year) in secondary school children.

\section{Method}

\section{Participants}

The sample comprised 9- to 12-year-old children (18 boys, 27 girls; at the beginning of the study children's mean age was 10 years and 9 months; $S D=6.00$ months) from a secondary school in Giessen, Germany. Participants had a mean fluid intelligence score of $M=107.38(S D=13.33)$. Hence, average intelligence scores were slightly higher than the published norms. The sample showed diversity with respect to parental education: for $40 \%$ of the children neither parent had a university degree, for $28.6 \%$ of the children one parent had a university degree, and for $31.4 \%$ of the children both parents had a university degree. The amount of formal music lessons outside school was heterogeneous across the sample. In sum $32.6 \%$ of the children had never had music lessons, $27.9 \%$ had up to 2 years of music lessons, $27.9 \%$ had 2 to 3 years of music lessons, and $11.6 \%$ had more than 3 years of music lessons (whole sample average of music lessons: $M=23.72, S D=$ 28.83).

\section{Material}

As relevant background variables socioeconomic status (SES), gender, age, amount of music lessons, and intelligence were measured. As predictor variable singing abilities were assessed and as criterion measure phonological skills were tested.

Parents completed a demographic questionnaire that asked for information about their education as one possible measure of SES. Mothers' and fathers' education was initially coded as a dichotomous variable ( 0 for "no university degree" and 1 for "a university degree"). For the statistical analyses, parental education was collapsed into a single variable: 0,1 , or 2 parents with a university degree. The demographic questionnaire was also used to assess gender, age, and amount of music lessons.

The amount of music lessons was reported by the parents. They provided details about their children's former and current private music lessons. An overall score of music lessons in months was computed for each child on the basis of this information. If a child played more than one instrument at a time, the months for each instrument were summed up. 
Intelligence was assessed with a short form of the Hamburg-Wechsler-Intelligenztest für Kinder (HAWIK III; Tewes, Rossmann, \& Schallberger, 2000), which consisted of two verbal and two performance subtests. The verbal subtests were the "vocabulary test" and the "information test", the performance subtests consisted of the "picture arrangement test" and the "mosaic test". The four subtest scores were used to calculate an estimate of full-scale IQ according to the formula by Schallberger (2005).

Singing abilities were measured with the song learning subtest from the music screening for children (Jungbluth \& Hafen, 2005). Children learned and sang a 6-bar-song (see Figure 1). Initially, the whole song was played from CD (sang by a child) for the children. After listening to the six bars of the song, pairs of two bars (3 pairs $=6$ bars) were successively heard and repeated back through singing. Finally, participants listened to the entire song again and were then asked to sing back all 6 bars. The performance of each participant (12 bars of singing) was recorded and afterwards rated by two independent judges, rating melody contour, rhythm, starting tone, and intonation. For 8 of 12 bars a maximum of 3 points could be awarded (one for each feature: contour, intonation, rhythm) and for the 4 bars with starting tone evaluation a maximum of 4 points (one for each feature: starting tone, contour, intonation, rhythm) could be reached. Thus, overall participants could score a maximum of 40 on the song learning test. The interrater reliability was $r=.96$.

1. Children listen to the whole song

2. Children listen to a pair of bars and sing it back

II

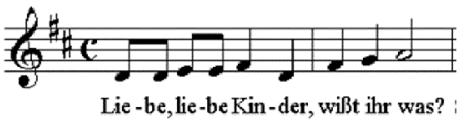

\begin{tabular}{|l|l|l|}
\hline starting tone & $0 / 0.5 / 1$ & - \\
\hline contour & $0 / 0.5 / 1$ & $0 / 0.5 / 1$ \\
\hline intonation & $0 / 0.5 / 1$ & $0 / 0.5 / 1$ \\
\hline rhythm & $0 / 0.5 / 1$ & $0 / 0.5 / 1$ \\
\hline
\end{tabular}

3. Children listen to the next pair of bars and sing it back

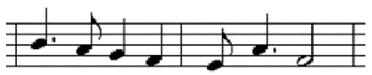

Sin - gen, sin - gen macht uns Spaß, si

\begin{tabular}{|l|l|}
\hline $0 / 0.5 / 1$ & - \\
\hline $0 / 0.5 / 1$ & $0 / 0.5 / 1$ \\
\hline $0 / 0.5 / 1$ & $0 / 0.5 / 1$ \\
\hline $0 / 0.5 / 1$ & $0 / 0.5 / 1$ \\
\hline
\end{tabular}

4. Children listen to the last pair of bars and sing it back

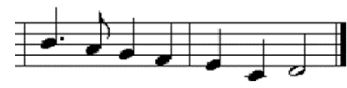

sin - gen, sin -gen macht uns Spaß!

\begin{tabular}{|l|l|}
\hline $0 / 0.5 / 1$ & - \\
\hline $0 / 0.5 / 1$ & $0 / 0.5 / 1$ \\
\hline $0 / 0.5 / 1$ & $0 / 0.5 / 1$ \\
\hline $0 / 0.5 / 1$ & $0 / 0.5 / 1$ \\
\hline
\end{tabular}

5. Children listen to the whole song and sing the whole song back

II

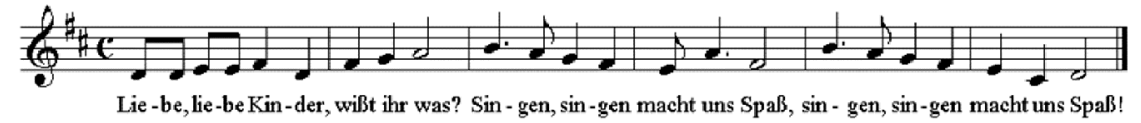

\begin{tabular}{|l|l|l|l|l|l|l|}
\hline starting tone & $0 / 0.5 / 1$ & - & - & - & - & - \\
\hline contour & $0 / 0.5 / 1$ & $0 / 0.5 / 1$ & $0 / 0.5 / 1$ & $0 / 0.5 / 1$ & $0 / 0.5 / 1$ & $0 / 0.5 / 1$ \\
\hline intonation & $0 / 0.5 / 1$ & $0 / 0.5 / 1$ & $0 / 0.5 / 1$ & $0 / 0.5 / 1$ & $0 / 0.5 / 1$ & $0 / 0.5 / 1$ \\
\hline rhythm & $0 / 0.5 / 1$ & $0 / 0.5 / 1$ & $0 / 0 / 0.5 / 1$ & $0 / 0.5 / 1$ & $0 / 0.5 / 1$ & $0 / 0.5 / 1$ \\
\hline
\end{tabular}

Figure 1. The song employed in the singing abilities test, along with information about the experimental procedure and accuracy scoring. 
Phonological awareness was measured with three subtests from the BAKO (Basis Kompetenz für Lese- und Rechtschreibleistung; Stock, Marx, \& Schneider, 2003): a) Segmentation of pseudo words, b) determination of vowel length, c) words backwards. We decided to apply the subtests that focused the most on individual phonemes of whole words or pseudo words and the segmentation of these:

a. In the segmentation of pseudo words task participants heard a pseudo word from a CD and had to segment it into its phonemes. For example "blims" could be segmented into $/ \mathrm{b} /-\mathrm{l} / \mathrm{/} / \mathrm{/} / \mathrm{/} / \mathrm{m} / \mathrm{-} / \mathrm{s} /$. A total of 8 items were segmented that way. For each correctly segmented item 1 point was awarded.

b. In the vowel length determination task participants listened to four words (real words and pseudo words) and had to decide which word differed in the middle (vowel length) from the other three words. Participants reported the target word and then proceeded to the next row of four words. Overall, 10 four-word rows were played to the participant. They received 1 point for each correctly identified target word that differed in the middle in vowel length from the other three words.

c. In the words backwards task participants listened to words or pseudo words from a CD and repeated them backwards. For example, after listening to the word "ligo" participants had to say "ogil". For each correct response participants received 1 point. The subtest consisted of 18 items, which results in a maximum of 18 points.

\section{Procedure}

Participants were tested three times over the course of two years. The first test wave (T0) was separated by one year from T1 and after a second year T2 took place.

At T0 parents completed the demographic questionnaire (SES, age, gender, music lessons), children's intelligence was assessed, children worked on the phonological awareness task, and singing abilities were tested. The tests were administered in the same sequence to all children. Each child took a short break halfway through the individual test session (after the intelligence test). At T1 the demographic questionnaire was completed by the parents and children's phonological awareness was measured. At T2 again each child completed the phonological awareness tests and parents filled out the demographic questionnaire.

For all these test waves the test protocol was very similar. The demographic questionnaire was sent via mail or email to the participants prior to the individual testing sessions. Parents were requested to complete the questionnaire. At each time point children were tested in a quiet room by a female assistant trained in administering the musical production test (song learning task) and the cognitive tests (phonological awareness, intelligence). At the end of the test session all children received a small gift and a certificate of attendance as a means of thanking them for their participation.

\section{Results}

The primary dependent variable of this study is the phonological awareness score assessed at the three different time points. The only dynamic predictor is time as defined by the three test waves (T0, T1, T2). The static predictor of primary interest in this study is the score on the song learning task taken at T0. In addition, we also aimed to compare song learning ability at T0 to the other static predictors assessed (age, gender, 
music lessons, intelligence, parental education). Table 1 displays descriptive statistics for IQ, song learning and phonological awareness.

Table 1

Minimum, Maximum, Mean, and Standard Deviation for IQ, Song Learning, and Phonological Awareness

\begin{tabular}{|c|c|c|c|c|c|c|c|c|c|c|c|c|}
\hline \multirow[b]{2}{*}{ Measure } & \multicolumn{4}{|c|}{ TO } & \multicolumn{4}{|c|}{ T1 } & \multicolumn{4}{|c|}{ T2 } \\
\hline & Min & Max & $M$ & $S D$ & Min & Max & $M$ & $S D$ & Min & Max & $M$ & $S D$ \\
\hline IQ & 80.19 & 148.06 & 107.38 & 13.33 & - & - & - & - & - & - & - & - \\
\hline Song learning & 11.50 & 38.00 & 26.13 & 5.97 & - & - & - & - & - & - & - & - \\
\hline Phonological awareness & 5.00 & 28.00 & 16.18 & 6.50 & 8.00 & 29.00 & 18.92 & 5.55 & 11.00 & 32.00 & 24.39 & 6.04 \\
\hline
\end{tabular}

Note. "-" = not assessed at this wave of testing.

Our data analysis strategy comprised two steps. In the first step, we computed all pairwise correlations between the phonological awareness (PA) scores at the three time points of measurement and the song learning score as well as the remaining predictor variables measured at T0. This first step aimed to establish whether PA scores across the three time points were robustly correlated to each other and as well as to song learning and the remaining predictors. In a second step, we computed a series of linear mixed effects models to model the change in PA across time and to identify any predictors that would significantly affect the absolute level of $\mathrm{PA}$ and its change over time.

\section{Correlational Analysis}

The correlational relationships between the phonological awareness at all three time points and the static predictors are given in Figure 2. The corresponding confidence intervals and $p$ values are given in Table A1 (see Appendix). 
$10 \quad 20$
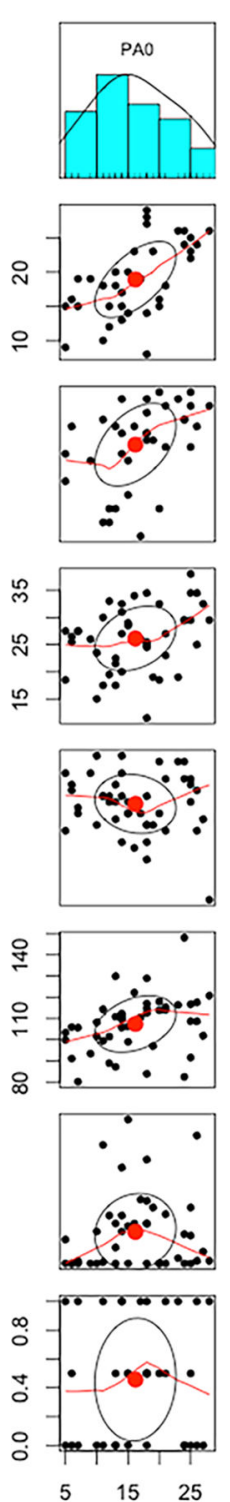
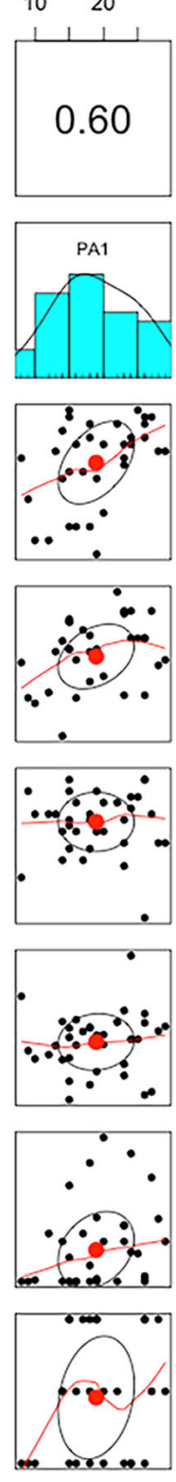

(1)

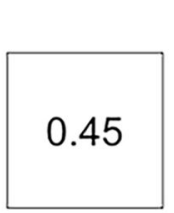

$\begin{array}{lll}15 & 25 & 35\end{array}$
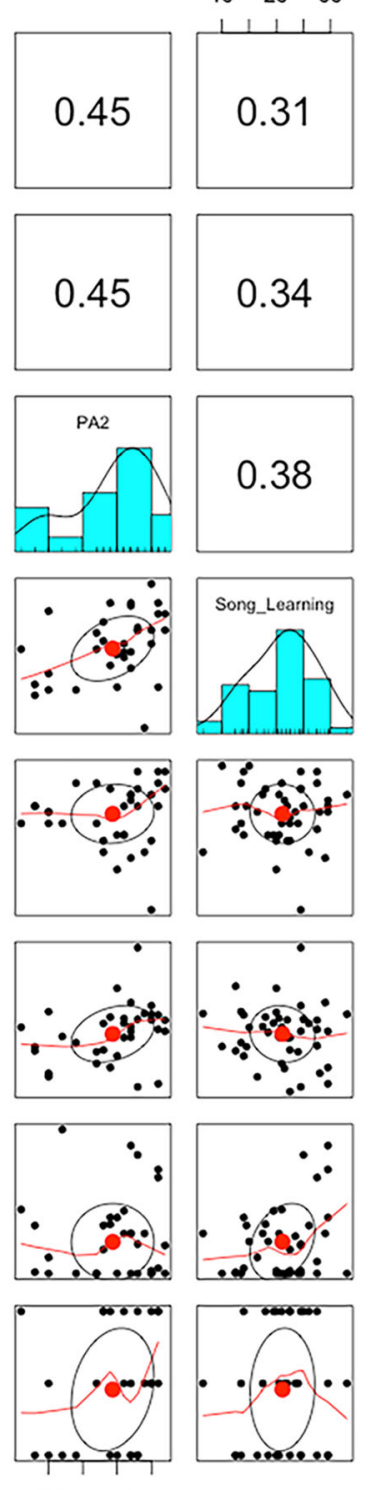
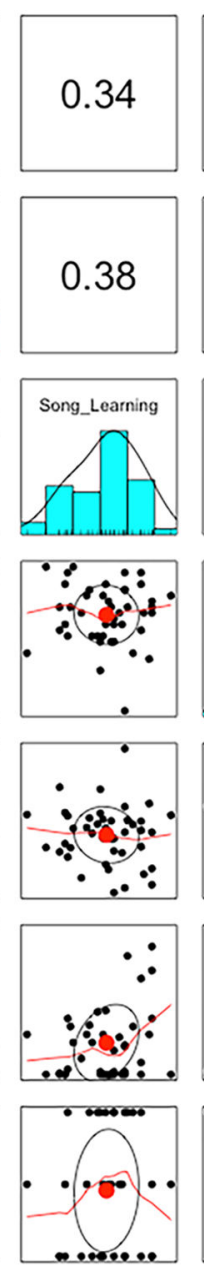

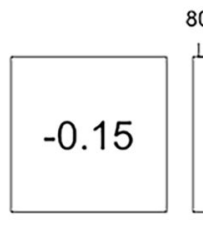

$80 \quad 110 \quad 140$
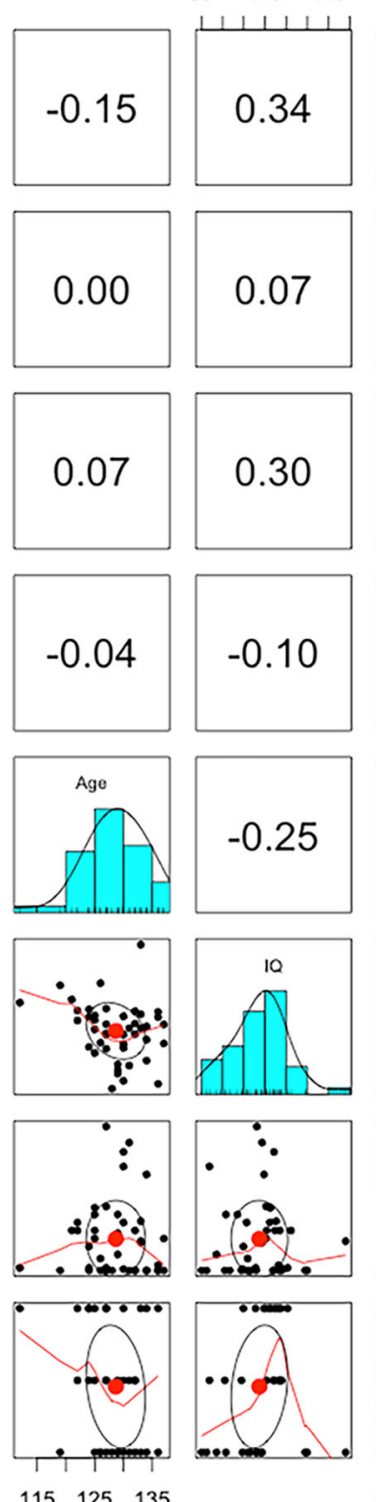
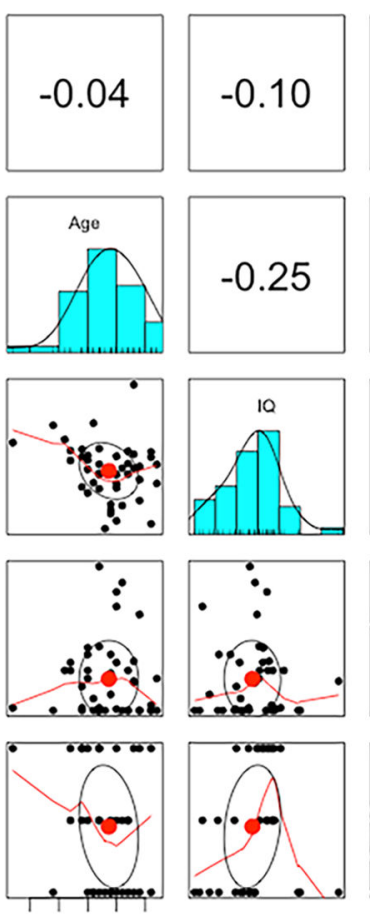

$115 \quad 125 \quad 135$

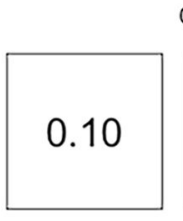

$\begin{array}{lll}0.0 & 0.4 & 0.8\end{array}$
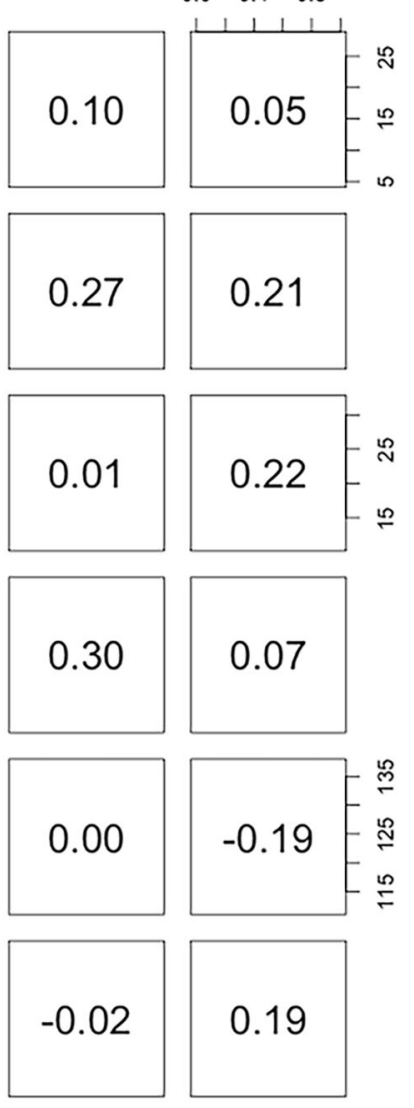

0.19
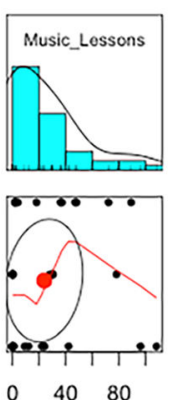

Figure 2. Univariate as well as bivariate distributions and correlations.

Note. Univariate distributions are graphically depicted in the diagonal of the figure. Bivariate distributions of all pairs of variables are shown in the lower left triangle of the figure. Pearson correlation coefficients of all pairs of variables are given in the upper right triangle. Phonological Awareness Scores measured at the three time points are abbreviated with PA0, PA1, PA2. Correlations coefficients $\geq|.31|$ are significant at the $p<.05$ level (not corrected for multiple comparisons). This applies for example to the negative correlation between Age and IQ that is not significant $(p=.10)$ even before correcting for multiple comparisons. 95\% confidence intervals and $p$-values (uncorrected and corrected for multiple testing) are given in Table A1 (see Appendix).

Figure 2 shows that he coefficients for the correlations between song learning ability and PA across all three measurement points (PA0, PA1, PA2) are fairly stable and are of moderate strengths, ranging between .31 and .38. In addition, PA scores are also related to intelligence and to a lesser degree to parental education 
and music lessons. However, the patterns of correlations for these additional predictors are less stable than for song learning ability.

\section{Mixed Effects Modelling}

In a next step, we consider the relationship of the PA scores across the three test waves. Figure 3 shows a clear increase of PA over time which strongly suggests the inclusion of time as a predictor in the subsequent statistical models.

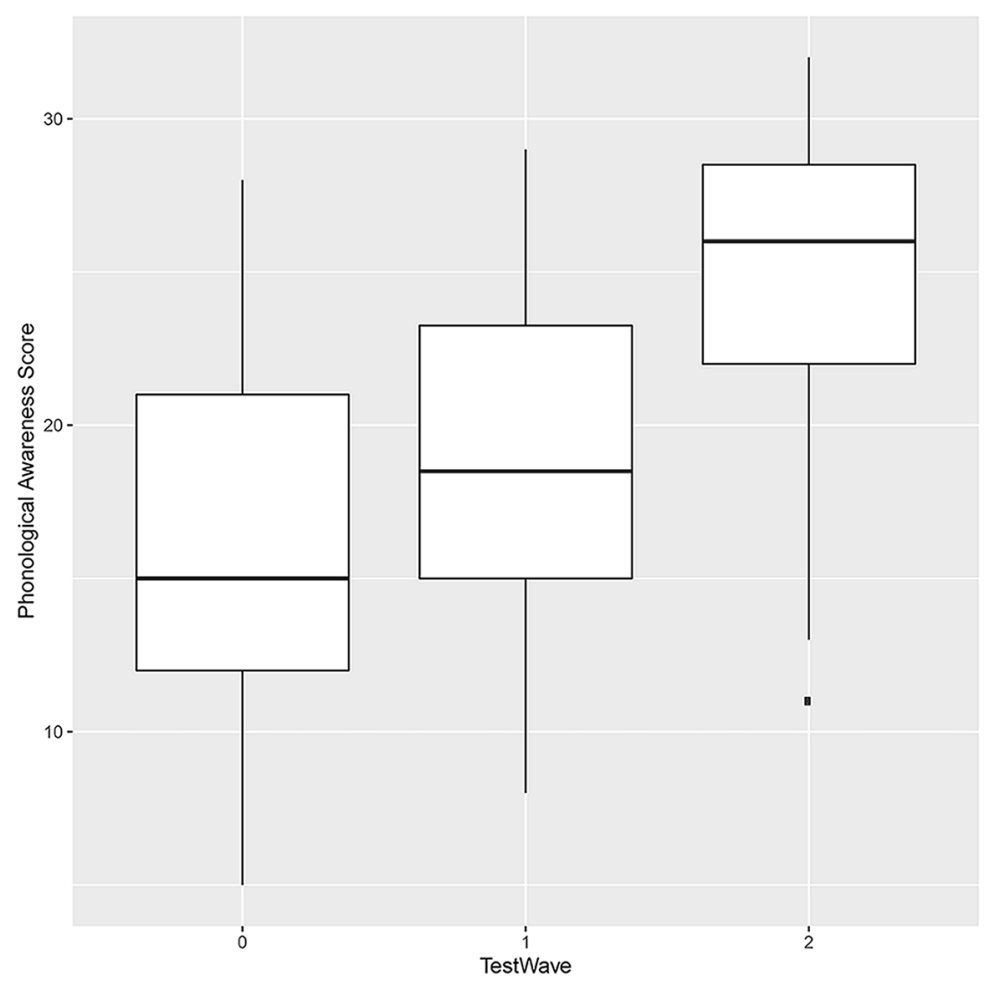

Figure 3. Boxplots of phonological awareness scores across the three test waves.

Following the analytical approach outlined by Long (2012) we used linear mixed effects models to assess the influence of the static predictors on the development of phonological awareness across time. Mixed effects models are similar to repeated measures ANOVA models but have a number of desirable features that make them suitable for this type of developmental data. Among the advantages of mixed effects models over traditional models (e.g., repeated measures ANOVA,) that Long (2012, p. 21) discusses are their ability to use all available information in the presence of missing data, the option to allow for individual differences when modelling change over time, and their ability to incorporate predictors of different types (i.e., static vs dynamic as well as quantitative or categorical variables).

Initially, we selected the random effects structure by comparing three models that all used time as fixed effect predictor variable but differed in their random effects for participants (random intercepts, random intercepts and uncorrelated slopes, random intercepts and correlated slopes). Likelihood ratio tests indicated that random intercepts were sufficient $(p>.28)$ and were therefore used as the only random effects in subsequent modelling stages. This result was confirmed by a comparison of three latent growth models (see e.g., Ghisletta \& 
McArdle, 2012 for an introduction) which were specified to have a) just an intercept, b) an intercept plus uncorrelated slope, and c) intercept plus correlated slope. Likelihood ratio tests as well as a comparison of the Bayesian information criterion (BIC) both suggested that the intercept-only model had the best model fit. This indicates that in this dataset there is little evidence for individual differences in terms of the rate of change over time and therefore the following models only consider individual differences in terms of the absolute level (i.e., intercept) of PA scores. The intra-class correlation coefficient (ICC) for the mixed effects model (conditional on time as predictor) was .391 , suggesting that phonological awareness scores are clustered within participants and that mixed effects modelling represents a suitable analysis technique.

In a second step, we selected the model's fixed effects from the static predictors following a multi-model comparison strategy as suggested by Burnham and Anderson (2002). We computed the corrected Akaike information criterion (AICc) for all possible models arising from the combination of the six static predictors (song learning ability, age, gender, music lessons, intelligence, parental education) in addition to time, which was included in all models. The top five models with the best AICc scores are given in Table 2.

Table 2

Coefficients of the Top Five Models With Best (i.e., Lowest) AICc Scores With Their Fixed Effect Predictors

\begin{tabular}{|c|c|c|c|c|c|c|c|c|c|c|c|c|}
\hline $\begin{array}{l}\text { Model } \\
\text { rank }\end{array}$ & Intercept & Age & Gender & IQ & $\begin{array}{l}\text { Music } \\
\text { lessons }\end{array}$ & $\begin{array}{c}\text { Parental } \\
\text { education }\end{array}$ & $\begin{array}{c}\text { Song } \\
\text { learning }\end{array}$ & Time & $d f$ & logLik & $\mathrm{AICc}$ & $\Delta$ \\
\hline 1 & -86.410 & & & 0.12550 & & & 0.4285 & 3.861 & 6 & -266.403 & 545.9 & 0.00 \\
\hline 2 & -75.510 & & + & 0.11250 & & & 0.4226 & 3.870 & 7 & -266.106 & 547.6 & 1,78 \\
\hline 3 & -82.680 & & & 0.11980 & & 0.8639 & 0.4221 & 3.854 & 7 & -266.299 & 548.0 & 2.16 \\
\hline 4 & -81.660 & & & 0.12440 & 0.013420 & & 0.4035 & 3.845 & 7 & -266.301 & 548.0 & 2.17 \\
\hline 5 & -111.300 & 0.018220 & & 0.12710 & & & 0.4281 & 3.858 & 7 & -266.396 & 548.2 & 2.36 \\
\hline
\end{tabular}

Note. AICc = Akaike information criterion. Time was entered a-priori as fixed effect predictor into all models and therefore the coefficient for Time is not displayed in the table. All other fixed effect predictors were subjected to the variable selection procedure.

All top five models include song learning ability and IQ as predictors, which provides strong evidence for the association of intelligence as well as song learning ability with phonological awareness. Gender, parental education, music lessons and age also featured in some of the top five models. However, the empirical support for these additional variables as predictors is weaker than for song learning ability and intelligence because the model with the best fit containing only song learning ability and intelligence had a considerably better AICc value than the second best model. In addition, song learning ability and intelligence are the only predictors that are included in all top five models. Finally, the model only including song learning ability and IQ is simpler than the remaining models among the top five and hence should be preferred according to Occam's Razor (MacKay, 2003). Thus, the model only including song learning ability and intelligence (besides time) as predictors was selected as the final model. This final model also had a better fit to the data than models with an additional interaction terms of time $\mathrm{x}$ song learning ability and time $\mathrm{x} I \mathrm{Q}$ according to the AICc and a likelihood ratio test $(p$ $>$.99). This suggests that song learning ability and intelligence are only associated with the absolute level of PA but not with the growth rate of PA over time.

As shown in Table 3, the coefficients of the final model for time as well as song learning ability and IQ are all significant and positive indicating that phonological awareness increases over time and is also higher for children with a higher IQ and higher song learning ability. Very similar coefficient estimates were obtained for 
song learning $(\beta=0.372, p=.001)$ and $\mathrm{IQ}(\beta=0.127, p=.012)$ from a latent growth model that included song learning and IQ as predictors of the model's intercept. The mixed effects model has a moderate to strong effect size of $R_{\text {marginal }}^{2}=.37$ and $R_{\text {conditional }}^{2} .64$ (Nakagawa, Johnson, \& Schielzeth, 2017) and the residuals of the model show a good approximation to a normal distribution with the exception of two outliers on the left-hand side of the distribution.

Table 3

Summary of the Best Fitting Mixed Effects Model Predicting Phonological Awareness, Including 95\% Confidence Intervals of the Coefficients

\begin{tabular}{lccccccc}
\hline Measure & Coefficient & SE & $\boldsymbol{d f}$ & $\boldsymbol{t}$ & $\boldsymbol{p}$ & $\mathbf{C l}_{\text {lower }}$ & $\mathbf{C l}_{\text {upper }}$ \\
\hline Intercept & -8.16588 & 6.69475 & 37.17558 & -1.220 & .23024 & 21.1472564 & 47.432 .324 \\
Time & 3.90094 & 0.50624 & 73.54441 & 7.706 & $<.001$ & 2.90766028 & 49.029 .395 \\
IQ & 0.13211 & 0.05258 & 37.56307 & 2.513 & .01639 & 0.03071432 & 0.2339341 \\
Song learning & 0.37628 & 0.11852 & 38.03788 & 3.175 & .00297 & 0.14771759 & 0.605827 \\
\hline
\end{tabular}

A graphical display of the effects of time and song learning ability as well as IQ on phonological awareness is given in Figure 4 and Figure 5 where the participant sample is cut into four equally sized groups with different levels of song learning ability.

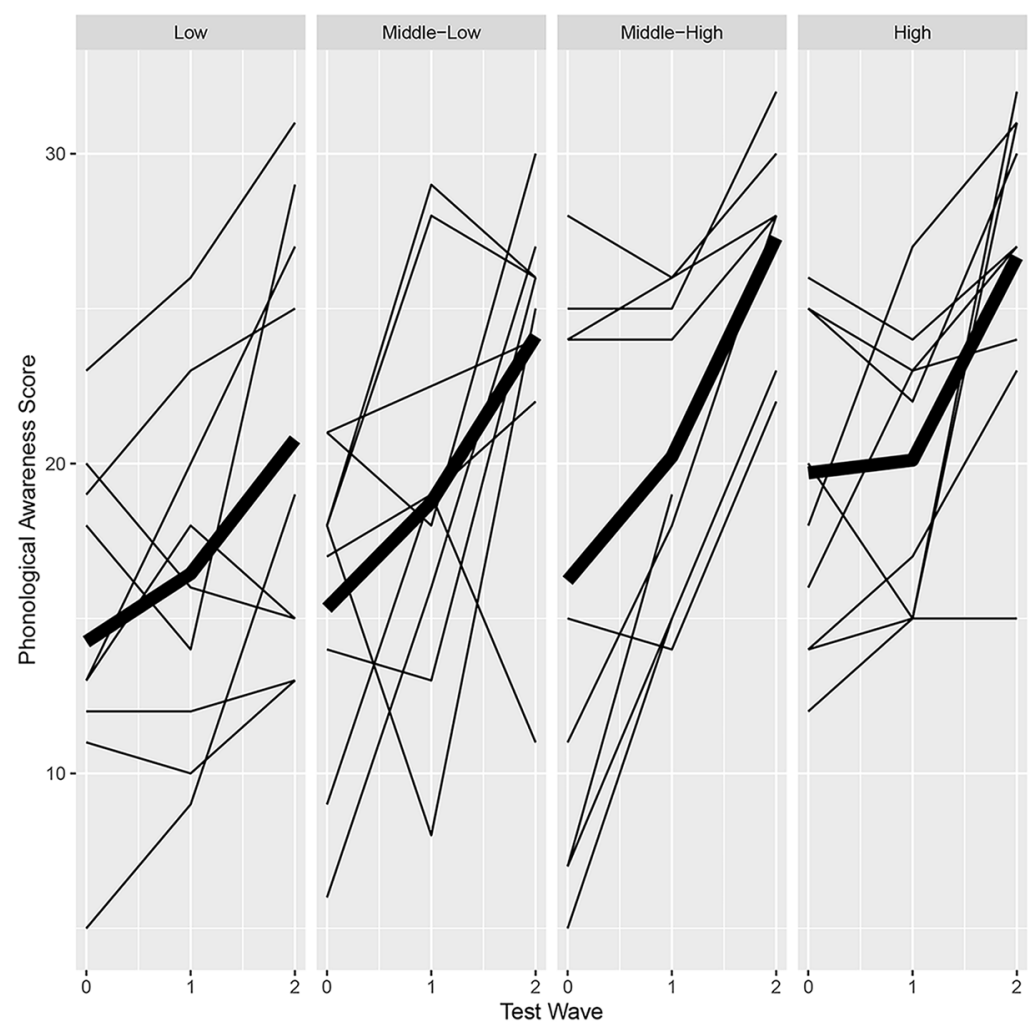

Figure 4. Development of phonological awareness across time for four different levels of song learning ability.

Note. Thick black lines represent mean values and thin lines represent the values of individual participants. Note that the categorization into four groups of song learning ability is only done for the purpose of this graphical display. For the statistical modelling reported above song learning ability was treated as a continuous variable. 


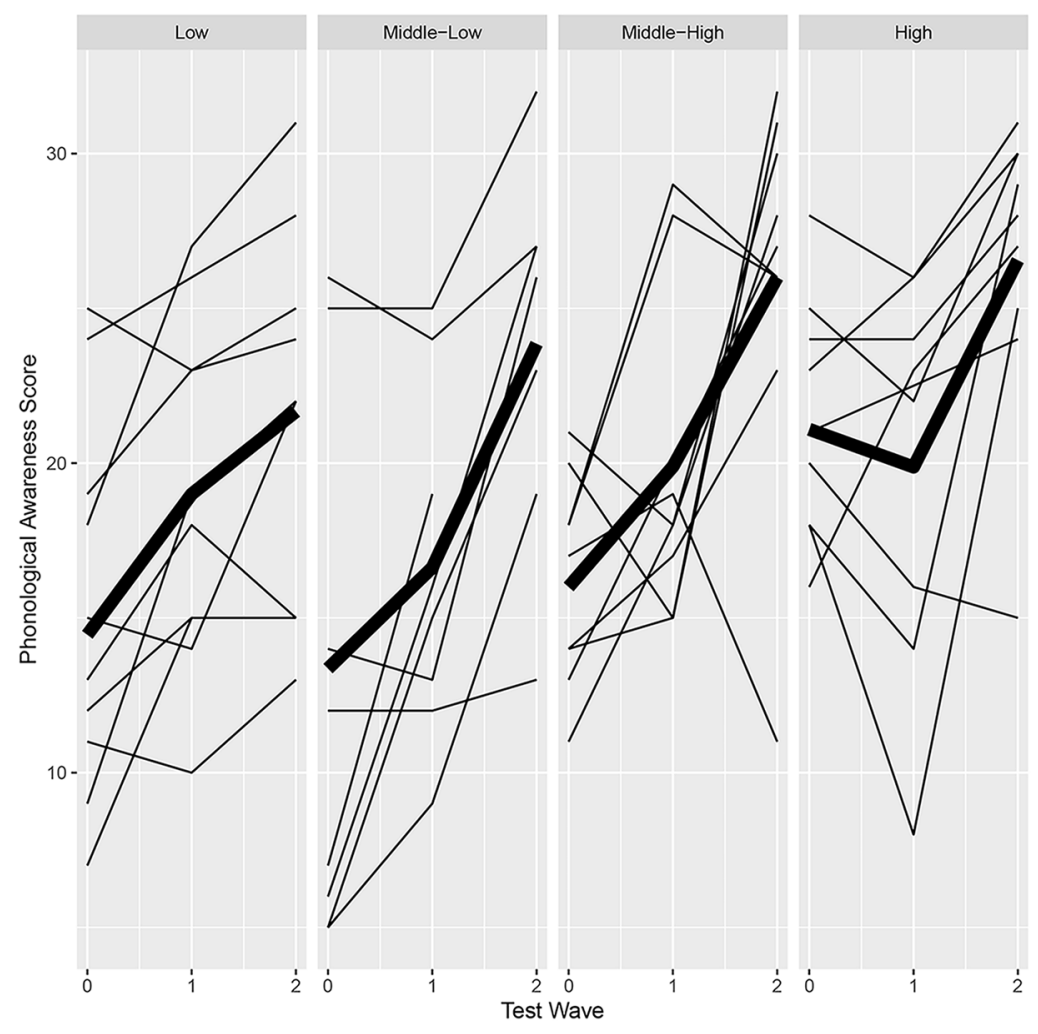

Figure 5. Development of phonological awareness across time for four different levels of IQ.

Note. Thick black lines represent mean values and thin lines represent the values of individual participants. Note that the categorization into four groups of $I Q$ is only done for the purpose of this graphical display. For the statistical modelling reported above IQ was treated as a continuous variable.

The mean lines in Figure 4 show that song learning ability is positively related to the absolute level of phonological awareness. However, the increase (slope) in phonological awareness across time does not seem to be related to song learning ability in any systematic way. Figure 4 also shows the large amount of individual differences in the development of phonological awareness across all levels of song learning ability. The amount of individual variation in the development of phonological awareness appears to be equally strong for the four groups of IQ displayed in Figure 5.

\section{Discussion}

This longitudinal study investigated whether musical abilities, singing in particular, are associated with phonological awareness in secondary school children. Furthermore, we tested whether singing ability can predict the development of phonological awareness over a time course of two years in 9- to 12-year-old children. We found that song learning abilities were significantly correlated with phonological awareness scores at all three test waves across the two-year duration of the study. Beyond that, it was possible to predict phonological awareness over time statistically from singing abilities. The model that employed song learning abilities, and test wave showed the best fit to the data and represents a parsimonious explanatory model of the development of phonological awareness in 9 to 12-year old children and its relationship with singing ability. The model 
shows that singing ability predicts the absolute level of phonological awareness but not the rate of development (slope) of phonological awareness over time. It is up to future studies to determine whether the developmental growth rate for phonological awareness is indeed independent of singing ability or whether the independence of growth rate and singing ability in this study is due to the study's relatively short duration, the small sample size, or the age range of the participants.

Our results are in accordance with earlier findings showing that singing is associated with phonological awareness in 3-year-old children (Bryant et al., 1989). Though, we assessed singing abilities with a different task that and potentially can be considered more natural by the participants. Whereas in the Bryant et al. (1989) study the knowledge (reciting) of nursery rhymes was used as a proxy for singing abilities, we employed a song learning task. Hence our study extends their findings in terms of using a more direct measure of singing skills and also in terms of the age group under investigation: We followed 9- to 12-year-old children's development for two years. Concerning associations between phonological awareness and musical abilities in older age groups our study goes along well with the study by Steinbrink and colleagues (2019). They found an association between musical abilities and PA not only in preschoolers but also in third-graders. In sum, the results of our study and the Steinbrink study point towards a persisting association between phonological awareness and musical abilities also in children older than the preschool years. However, the musical abilities under investigation differed between the current study and the study by Steinbrink et al. (2019) (singing abilities vs. rhythmic abilities). Our findings also fit with the results published by Patscheke and colleagues (2019). They were able to train phonological awareness with an intervention that focused on pitch. As part of the training, preschoolers were given singing tasks, intonation tasks, and also pitch perception tasks. Hence, singing abilities were only trained among other things but still there was a positive impact on phonological awareness using a training intervention that contained singing. In this respect our findings go together neatly with the results reported by Patscheke et al. (2019), extending the age group under investigation and only focusing on a single aspect (i.e., singing). Furthermore, the empirical evidence presented here also fits with the findings by Degé et al. (2015) who pointed out that in preschoolers an association between singing abilities and phonological awareness is present. We extended their findings by showing that singing abilities are not only associated with phonological awareness, but could also be used to predict phonological awareness over a time course of two years. Moreover, we provide support for their claim that a prominent association between singing and phonological awareness exists. Additionally, we could show this association in an older age group.

Taken together, it seems highly likely that singing provides a unique way for accessing phonemes as postulated by Fisher and McDonald (2001). However, using the current empirical approach we were not able to identify what the effective feature of singing or song learning is. It may be the stressing, repeating, and lengthening of syllables, words, and lyrics, but other features of singing and song learning might also be effective.

In broader developmental terms, our results show that the close relationship between language and musical abilities that is postulated for the early years of development can still be found in older children (secondary school children); at least between singing and phonological awareness. Most research concerning phonological awareness is carried out with kindergartners and preschoolers, but rarely with in older children. The general focus on younger age groups in this area of research is explained by the crucial role that phonological awareness plays for learning to read and write. Though from a theoretical as well as educational perspective it is important to know how long the association between musical abilities and phonological awareness persists. We could show that it is still present in 9- to 12-year-old children. 
Above that, we do believe that our findings can also be relevant for research focusing on using music as an intervention to promote phonological awareness. We assume that the association between singing and phonological awareness found in 9- to 12-year-old children is comparable to associations that can be found in preschoolers. Hence, our results along with findings by Patscheke and colleagues (2019) suggest that singing should play an important role in intervention programs for verbal abilities and literacy skills.

\section{Limitations and Future Directions}

This study has three important limitations: Firstly, the relatively small sample size. This precludes far reaching generalizations. Therefore, it is important that future studies replicate our results with larger sample sizes. Secondly, the study only comprised 3 test waves across two years. However, for the robustness and the generalizability of the statistical model it would have been advantageous to include data from more test waves. Thirdly, the song learning task could be considered as relying heavily on working memory or good language processing abilities, because it requires that song and text are reproduced. Furthermore, the song learning task used here has not been published a so far and lacks information about reliability and validity. However, in real life situations like those occurring in daycare centers or schools (even in families) learning to sing a song is always confounded with working memory and speech. Hence, the process that is mimicked by the test is relatively natural for song learning in children at our participants' age. Regarding working memory, it is clear that learning a song produces working memory load. Though, the text is very simple and the procedure of testing (listening, singing two-bar pairs and finally singing the entire song, see Figure 1) did not appear to be overly demanding for the participants in this experiment. Consequently, we do not assume that the working memory load required for performing the task was overly high for the 9- to 12-year-old normally developing children of this sample. The same might hold true for the language demands of the task, because words are simple and often repeated as well as not part of the scoring procedure. However, it might still be a useful to simplify the song learning task by asking participants to only use a single syllable for singing (e.g., "lalalala") instead of real lyrics. In addition, it could also be considered a limitation that we only assessed song learning as a measure for singing abilities. Surely, there are further important aspects of singing ability than song learning. It is possible to get a rather detailed picture with the song learning task, because it measures production but also necessarily requires perceptual abilities in the learning phase. However, creative aspects of singing abilities (improvisation, composition, daily use, spontaneous song production) have not been part of the assessment. Hence, it remains to be seen if creative aspects are important for the association between singing and phonological awareness. Above and beyond the need for a replication with a larger sample and more test waves, it would also be interesting for future research to investigate what might be a special feature of singing abilities that links them to phonological awareness. This knowledge can potentially provide a seminal basis for designing musical intervention studies that target the enhancement of language abilities in general or phonological abilities in particular.

\section{Funding}

The authors have no funding to report.

\section{Competing Interests}

The authors have declared that no competing interests exist. 


\section{Acknowledgments}

The authors have no support to report.

\section{Ethical Approval}

The study was conducted in full accordance with the Ethical Guidelines of the German Association of Psychologists (DGPs). Informed consent was obtained from the parents for each participant.

\section{References}

Anvari, S. H., Trainor, L. J., Woodside, J., \& Levy, B. A. (2002). Relations among musical skills, phonological processing, and early reading ability in preschool children. Journal of Experimental Child Psychology, 83(2), 111-130. https://doi.org/10.1016/S0022-0965(02)00124-8

Besson, M., Chobert, J., \& Marie, C. (2011). Transfer of training between music and speech: Common processing, attention, and memory. Frontiers in Psychology, 2, Article 94. https://doi.org/10.3389/fpsyg.2011.00094

Bolduc, J. (2009). Effects of a music programme on kindergartners' phonological awareness skills. International Journal of Music Education, 27(1), 37-47. https://doi.org/10.1177/0255761408099063

Bruck, M. (1992). Persistence of dyslexics' phonological awareness deficits. Developmental Psychology, 28(5), 874-886. https://doi.org/10.1037/0012-1649.28.5.874

Bryant, P. E., Bradley, L., Maclean, M., \& Crossland, J. (1989). Nursery thymes, phonological skills and reading. Journal of Child Language, 16(2), 407-428. https://doi.org/10.1017/S0305000900010485

Burnham, K. P., \& Anderson, D. B. (2002). Model selection and multimodel inference: A practical information-theoretic approach. New York, NY, USA: Springer.

Chobert, J., François, C., Velay, J. L., \& Besson, M. (2014). Twelve months of active musical training in 8- to 10-year-old children enhances the preattentive processing of syllabic duration and voice onset time. Cerebral Cortex, 24(4), 956-967. https://doi.org/10.1093/cercor/bhs377

Davidson, L. (1994). Songsinging by young and old: a developmental approach to music. In R. Aiello (Ed.), Musical perceptions (pp. 99-130). New York, NY, USA: Oxford University Press.

Degé, F., Kubicek, C., \& Schwarzer, G. (2015). Associations between musical abilities and precursors of reading in preschool aged children. Frontiers in Psychology, 6, Article 1220. https://doi.org/10.3389/fpsyg.2015.01220

Degé, F., \& Schwarzer, G. (2011). The effect of a music program on phonological awareness in preschoolers. Frontiers in Psychology, 2, Article 124. https://doi.org/10.3389/fpsyg.2011.00124

Fernald, A. (1991). Prosody in speech to children: Prelinguistic and linguistic functions. Annals of Child Development, 8, 43-80.

Fisher, D., \& McDonald, N. (2001). The intersection between music and early literacy instruction: Listening to literacy. Reading Improvement, 38, 106-115. 
Flaugnacco, E., Lopez, L., Terribili, C., Zoia, S., Buda, S., Tilli, S., . . Schön, D. (2014). Rhythm perception and production predict reading abilities in developmental dyslexia. Frontiers in Human Neuroscience, 8, Article 392. https://doi.org/10.3389/fnhum.2014.00392

Ghisletta, P., \& McArdle, J. J. (2012). Latent curve models and latent change score models estimated in R. Structural Equation Modeling, 19(4), 651-682. https://doi.org/10.1080/10705511.2012.713275

Gordon, R. L., Fehd, H. M., \& McCandliss, B. D. (2015). Does music training enhance literacy skills? A meta-analysis. Frontiers in Psychology, 6, Article 1777. https://doi.org/10.3389/fpsyg.2015.01777

Gromko, J. E. (2005). The effect of music instruction on phonemic awareness in beginning readers. Journal of Research in Music Education, 53(3), 199-209. https://doi.org/10.1177/002242940505300302

Herrera, L., Lorenzo, O., Defior, S., Fernandez-Smith, G., \& Costa-Giomi, E. (2011). Effects of phonological and musical training on the reading readiness of native- and foreign-Spanish-speaking children. Psychology of Music, 39(1), 68-81. https://doi.org/10.1177/0305735610361995

Huss, M., Verney, J. P., Fosker, T., Mead, N., \& Goswami, U. (2011). Music, rhythm, rise time and developmental dyslexia: Perception of musical meter predicts reading and phonology. Cortex, 47(6), 674-689.

https://doi.org/10.1016/j.cortex.2010.07.010

Jansen, H., Mannhaupt, G., Marx, H., \& Skowronek, H. (2002). Bielefelder Screening zur Früherkennung von LeseRechtschreibschwierigkeiten (2nd ed.). Göttingen, Germany: Hogrefe.

Jungbluth, A., \& Hafen, R. (2005). Musik- Screening für Kinder [Unpublished test material]. Vechta.

Koelsch, S., \& Siebel, W. A. (2005). Towards a neural basis of music perception. Trends in Cognitive Sciences, 9(12), 578-584. https://doi.org/10.1016/j.tics.2005.10.001

Küspert, P., \& Schneider, W. (2005). Hören, lauschen, lernen Sprachspiele für Kinder im Vorschulalter (5th ed.). Göttingen, Germany: Vandenhoeck \& Ruprecht.

Lamb, S. J., \& Gregory, A. H. (1993). The relationship between music and reading in beginning readers. Educational Psychology, 13(1), 19-27. https://doi.org/10.1080/0144341930130103

Long, J. D. (2012). Longitudinal data analysis for the behavioral sciences using R. Thousand Oakes, CA, USA: Sage.

MacKay, D. J. C. (2003). Information theory, inference, and learning algorithms. Cambridge, United Kingdom: Cambridge University Press.

Marx, P. (2007). Lese- und Rechtschreiberwerb. Paderborn, Germany: Schöningh UTB.

Masataka, N. (1999). Preference for infant-directed singing in 2-day-old hearing infants of deaf parents. Developmental Psychology, 35(4), 1001-1005. https://doi.org/10.1037/0012-1649.35.4.1001

McMullen, E., \& Saffran, J. R. (2004). Music and language: A developmental comparison. Music Perception, 21(3), 289-311. https://doi.org/10.1525/mp.2004.21.3.289

Moritz, C., Yampolskiy, S., Papadelis, G., Thomson, J., \& Wolf, M. (2013). Links between early rhythm skills, musical training, and phonological awareness. Reading and Writing, 26, 739-769. https://doi.org/10.1007/s11145-012-9389-0 
Nakagawa, S., Johnson, P., \& Schielzeth, H. (2017). The coefficient of determination R2 and intra-class correlation coefficient from generalized linear mixed-effects models revisited and expanded. Journal of the Royal Society, Interface, 14(134), Article 20170213. https://doi.org/10.1098/rsif.2017.0213

Norton, A., Winner, E., Cronin, K., Overy, K., Lee, D. J., \& Schlaug, G. (2005). Are there pre-existing neural, cognitive, or motoric markers for musical ability? Brain and Cognition, 59(2), 124-134. https://doi.org/10.1016/j.bandc.2005.05.009

Patel, A. D. (2008). Music, language, and the brain. Oxford, United Kingdom: University Press.

Patel, A. D. (2011). Why would musical training benefit the neural encoding of speech? The OPERA hypothesis. Frontiers in Psychology, 2, Article 142. https://doi.org/10.3389/fpsyg.2011.00142

Patscheke, H., Degé, F., \& Schwarzer, G. (2016). The effects of training in music and phonological skills on phonological awareness in 4- to 6-year-old children of immigrant families. Frontiers in Psychology, 7, Article 1647. https://doi.org/10.3389/fpsyg.2016.01647

Patscheke, H., Degé, F., \& Schwarzer, G. (2019). The effects fo training in rhythm and pitch on phonological awareness in four- to six-year-old children. Psychology of Music, 47(3), 376-391. https://doi.org/10.1177/0305735618756763

Peretz, I., \& Coltheart, M. (2003). Modularity of music processing. Nature Neuroscience, 6(7), 688-691. https://doi.org/10.1038/nn1083

Pratt, A. C., \& Brady, S. (1988). Relation of phonological awareness to reading disability in children and adults. Journal of Educational Psychology, 80(3), 319-323. https://doi.org/10.1037/0022-0663.80.3.319

Schallberger, U. (2005). Welches sind die nach statistischen Kriterien besten Kurzformen des HAWIK-III? Berichte aus der Abteilung Angewandte Psychologie, 32, 3-29.

Schneider, W., Kuspert, P., Roth, E., Vise, M., \& Marx, H. (1997). Short-and long-term effects of training phonological awareness in kindergarten: Evidence from two German studies. Journal of Experimental Child Psychology, 66(3), 311-340. https://doi.org/10.1006/jecp.1997.2384

Schneider, W., Roth, E., Küspert, P., \& Ennemoser, M. (1998). Kurz- und langfristige Effekte eines Trainings der sprachlichen (phonologischen) Bewusstheit bei unterschiedlichen Leistungsgruppen: Befunde einer Sekundäranalyse. Zeitschrift für Entwicklungspsychologie und Pädagogische Psychologie, 30(1), 26-39.

Schön, D., Boyer, M., Moreno, S., Besson, M., Peretz, I., \& Kolinksy, R. (2008). Songs as an aid for language acquisition. Cognition, 106(2), 975-983. https://doi.org/10.1016/j.cognition.2007.03.005

Skowronek, H., \& Marx, H. (1989). Die Bielefelder Längsschnittstudie zur Erkennung von Risiken der LeseRechtschreibschwäche. Heilpädagogische Forschung, 15, 38-49.

Stadler-Elmer, S. (2002). Kinder singen Lieder: Über den Prozess der Kultivierung des vokalen Ausdrucks. Münster, Germany: Waxmann.

Steinbrink, C., Knigge, J., Mannhaupt, G., Sallat, S., \& Werkle, A. (2019). Are temporal and tonal musical skills related to phonological awareness and literacy skills? - Evidence from two cross-sectional studies with children from different age groups. Frontiers in Psychology, 10, Article 805. https://doi.org/10.3389/fpsyg.2019.00805 
Stock, C., Marx, P., \& Schneider, W. (2003). BAKO 1-4 Basiskompetenzen für Lese-Rechtschreibleistungen. Göttingen, Germany: Beltz Test GmbH.

Tewes, U., Rossmann, P., \& Schallberger, U. (2000). Hamburg-Wechsler-Intelligenztest für Kinder III. Bern, Germany: Hans Huber.

Tierney, A., \& Kraus, N. (2014). Auditory-motor entrainment and phonological skills: Precise auditory timing hypothesis (PATH). Frontiers in Human Neuroscience, 8, Article 949. https://doi.org/10.3389/fnhum.2014.00949

Trainor, L. J. (1996). Infant preferences for infant-directed versus noninfant-directed playsongs and lullabies. Infant Behavior and Development, 19(1), 83-92. https://doi.org/10.1016/S0163-6383(96)90046-6

Welch, G. F. (2012). Singing and vocal development. In G. McPherson (Ed.), The child as musician: A handbook of musical development (pp. 441-461). Oxford, United Kingdom: Oxford University Press.

\section{Appendix}

Table A1

Pearson Correlation Coefficients, 95\% Confidence Intervals, and p Values (Corrected and Uncorrected for Multiple Testing) of the Correlational Data Analysis

\begin{tabular}{|c|c|c|c|c|c|}
\hline Correlated variable & $\mathrm{Cl}_{\text {lower }}$ & $r$ & $\mathrm{Cl}_{\text {upper }}$ & $\boldsymbol{p}_{\text {uncorrected }}$ & $\boldsymbol{p}_{\text {corrected }}$ \\
\hline PA0-PA1 & 0.34 & .60 & 0.77 & $<.01$ & $<.01$ \\
\hline PA0-PA2 & 0.13 & .45 & 0.68 & .01 & .19 \\
\hline PA0-Sng_L & 0.02 & .31 & 0.56 & .04 & .86 \\
\hline PA0-Age & -0.42 & -.15 & 0.15 & .33 & 1.00 \\
\hline PAO-IQ & 0.05 & .34 & 0.58 & .02 & .58 \\
\hline PA0-Msc_L & -0.21 & .10 & 0.39 & .53 & 1.00 \\
\hline PA0-Prn_E & -0.29 & .05 & 0.37 & .79 & 1.00 \\
\hline PA1-PA2 & 0.13 & .45 & 0.68 & .01 & .21 \\
\hline PA1-Sng_L & 0.00 & .34 & 0.60 & .05 & 1.00 \\
\hline PA1-Age & -0.33 & .00 & 0.33 & 1.00 & 1.00 \\
\hline PA1-IQ & -0.27 & .07 & 0.39 & .69 & 1.00 \\
\hline PA1-Msc_L & -0.07 & .27 & 0.56 & .12 & 1.00 \\
\hline PA1-Prn_E & -0.17 & .21 & 0.54 & .28 & 1.00 \\
\hline PA2-Sng_L & 0.05 & .38 & 0.64 & .03 & .65 \\
\hline PA2-Age & -0.27 & .07 & 0.39 & .71 & 1.00 \\
\hline PA2-IQ & -0.04 & .30 & 0.58 & .08 & 1.00 \\
\hline PA2-Msc_L & -0.34 & .01 & 0.35 & .98 & 1.00 \\
\hline PA2-Prn_E & -0.18 & .22 & 0.55 & .27 & 1.00 \\
\hline Sng_L-Age & -0.34 & -.04 & 0.26 & .77 & 1.00 \\
\hline Sng_L-IQ & -0.39 & -.10 & 0.21 & .54 & 1.00 \\
\hline Sng_L-Msc_L & -0.01 & .30 & 0.55 & .06 & 1.00 \\
\hline Sng_L-Prn_E & -0.28 & .07 & 0.40 & .70 & 1.00 \\
\hline Age-IQ & -0.51 & -.25 & 0.05 & .10 & 1.00 \\
\hline Age-Msc_L & -0.30 & .00 & 0.30 & .99 & 1.00 \\
\hline Age-Prn_E & -0.49 & -.19 & 0.15 & .27 & 1.00 \\
\hline IQ-Msc_L & -0.32 & -.02 & 0.29 & .91 & 1.00 \\
\hline IQ-Prn_E & -0.16 & .19 & 0.50 & .28 & 1.00 \\
\hline Msc_L-Prn_E & -0.21 & .13 & 0.44 & .45 & 1.00 \\
\hline
\end{tabular}

